1908

\title{
Marie von Ebner-Eschenbach
}

\author{
Betty Paoli
}

Follow this and additional works at: https://scholarsarchive.byu.edu/sophnf_essay

Part of the German Literature Commons

\section{BYU ScholarsArchive Citation}

Paoli, Betty, "Marie von Ebner-Eschenbach" (1908). Essays. 811.

https://scholarsarchive.byu.edu/sophnf_essay/811

This Article is brought to you for free and open access by the Nonfiction at BYU ScholarsArchive. It has been accepted for inclusion in Essays by an authorized administrator of BYU ScholarsArchive. For more information, please contact scholarsarchive@byu.edu, ellen_amatangelo@byu.edu. 


\section{[Marie von Ebner-Eschenbach]}

\section{Erzählungen. - Leopold Kompert und Marie v. Ebner-Eschenbach}

Es ist eine unleugbare Tatsache, daß die literarische Sympathie der Gegenwart sich von den Dichtungswerken in metrischer Form ab- und dafür um so entschiedener dem Roman, der Erzählung, der Novelle zuwendet. Zum Teil mag dies in dem realistischen Zug der Zeit begründet, zum Teil mag es dem Umstand zuzuschreiben sein, daß sich unter der jüngeren Poeten-Generation - und der Jugend gehört die Welt - weder ein Dramatiker noch ein Lyriker ersten Ranges befindet, während sie eine nicht geringe Anzahl bedeutender, zum Teil großartiger Erzählertalente aufzuweisen hat. Wie natürlich fühlt sich das Publikum von dem Gebiet, auf welchem ihm im Augenblick das Beste geboten wird, am meisten angezogen, und betätigt seinen Romanciers und Novellisten gegenüber ein reges, lebendiges Interesse. Ja, es geht in seiner Vorliebe für die Dichtungsform der Gegenwart so weit, daß es mitunter auch Werken von sehr mäßigem literarischen Wert eine Teilnahme und Verbreitung angedeihen läßt, über die man staunen muß. Freilich gleicht es dieses Übermaß von Empfänglichkeit nicht selten durch die gleichgiltige Aufnahme des Vortrefflichen wieder aus.

Um nur ein Beispiel anzuführen, möchte ich auf Louise v. François "Die letzte Reckenburgerin « hinweisen. Mit vollem Recht nennt Karl Hillebrand, der geist- und geschmackvolle Kenner, diesen Roman den besten, der seit 25 Jahren in Deutschland erschienen ist. Nichtsdestoweniger hat dieses wahrhaft ausgezeichnete Werk, das eine an die Droste erinnernde Geistestiefe und Gestaltungskraft bekundet, nur in einem verhältnismäßig kleinen Kreise die verdiente Würdigung gefunden; dem großen Publikum ist es bis auf den Titel unbekannt geblieben. So erwahrt sich der alte Spruch: daß auch Bücher ihre Schicksale haben, bald unter einem günstigen, bald unter einem ungünstigen Stern das Licht der Welt erblicken. Das läßt sich nicht ändern; auch hier macht der blinde Zufall sein Recht geltend. Um so mehr hat jedoch der einzelne dafür zu sorgen, daß er selbst, so viel er vermag, Gerechtigkeit übe und nach dem Maß seiner Kräfte den Weizen von der Spreu sondern helfe. Ich glaube in diesem Sinne zu handeln, indem ich die Lesewelt auf zwei neue literarische Erscheinungen aufmerksam mache, die sowohl durch die Wichtigkeit der 
darin behandelten Probleme, als durch das Talent und die Gesinnung, die sich darin aussprechen, sich vor vielen Erzeugnissen desselben Genres vorteilhaft auszeichnen. Ich meine damit Komperts Roman »Zwischen Ruinen " (Berlin 1875) und die soeben in Cottas Verlag erschienenen Erzählungen der Freiin Marie v. Ebner-Eschenbach.

Komperts Ruf als Erzähler ist längst fest begründet. Schon sein erstes Buch, »Aus dem Ghetto«, das er im Jahre 1848, also in einem nichts weniger als literaturfreundlichen Moment, veröffentlichte, fand eine so günstige Aufnahme, eine so rasche Verbreitung, daß wenige Monate später eine neue Auflage veranstaltet werden mußte. Bei dem Werk eines bis dahin gänzlich unbekannten und von keiner Reklame unterstützten Schriftstellers will dies nichs geringes bedeuten. In erster Linie hatte Kompert diesen großen und wohlverdienten Erfolg seinem Talent und dem richtigen Instinkt zu verdanken, der ihn gleich beim ersten Versuch erkennen ließ, unter welchem Zeichen ihm der Sieg verheißen sei. In zweiter Reihe kam der Umstand hinzu, daß der Stoff, den er gewählt hatte, in innerem Zusammenhang mit einer drängenden Frage der Zeit stand. Nicht als ob die Erzählungen aus dem jüdischen Volksleben, die 62 das Buch enthält, einen tendenziösen Charakter trügen - Kompert ist zu sehr Dichter, um auf anderem als künstlerischen Wege wirken zu wollen; allein aus der einfachen, wahrheitsgetreuen Darstellung des Tatsächlichen ging in diesem Falle ganz von selbst eine Anklage gegen die Intoleranz der die Juden betreffenden Gesetze und ein Plaidoyer für die Unterdrückten hervor. Davon abgesehen, fesselte das Buch durch die vollkommene Neuheit seines Gegenstandes, die Fremdartigkeit der Sitten, Zustände und Anschauungen, mit denen es den Leser bekannt machte, vor allem aber durch das überaus fein und geistreich ausgearbeitete Detail, mittels dessen es die Absonderlichkeiten deutet und erklärt, die eine vielhundertjährige Isolierung im jüdischen Wesen großgezogen hat. Selbstverständlich ist hier nicht von jener Klasse Juden die Rede, welche, lange bevor die Gesetzgebung sich dazu entschloß, durch Bildung und geistigen Anschluß ans Allgemeine sich selbst emanzipierten, sondern von den unteren Schichten der jüdischen Bevölkerung, die, in Dörfern oder kleinen Landstädten lebend, mit ihrer christlichen Umgebung in keinem anderen als einem geschäftlichen Verkehr stehen, keine anderen Bildungsmittel benutzen als ihre heiligen Bücher, und kein anderes Glück kennen als das der Familie. Eine solche teils aufgezwungene, teils freiwillige Beschränkung des geistigen Blickes und der Gefühlssphäre muß notwendig dem Charak- 
ter viele seltsame, wunderliche Züge einprägen, einzelne Anlagen ungewöhnlich stark entwickeln, andere halb verkümmern lassen. Uns das Verständnis der Eigentümlichkeiten des Lebens im Ghetto näher zu bringen, uns in einer durch schwere Leiden und lange Erniedrigung entstellten Volksphysiognomie das allgemein Menschliche, uns Verwandte, gewahren zu lassen, ein Gefühl der Zusammengehörigkeit mit denjenigen einzuflößen, die ein Gegenstand des Spottes und der Verachtung zu sein pflegten, das war die Aufgabe, welche Kompert sich schon bei seinem ersten Auftreten stellte, und die er seither mit einer tiefster Sympathie entspringenden Treue fast ausschließlich verfolgt hat. $\mathrm{Zu}$ ihr gesellte sich im Laufe der Jahre noch eine zweite, innerlichst mit ihr verbundene. Auch für das jüdische Volk war eine neue Zeit angebrochen; die gesetzlichen Schranken, welche es bis dahin in ungesunder Abgeschlossenheit gehalten hatten, fielen eine nach der anderen; die Wahl eines Lebensberufes wurde nicht länger durch engherzige Verordnungen beschränkt. Wenn aber auch de jure kein Ghetto mehr bestand, so waren doch die Anschauungen, die Denk- und Gefühlsweise, die er erzeugt hatte, keineswegs mit ihm entschwunden, und es entstand die Frage: in welchem Sinne und bis zu welchem Grade die bürgerliche Gleichstellung auf die jüdische Volksseele wirken werde. Diese Frage bildet den geistigen Kern von Komperts späteren Werken: »Böhmische Juden«, "Am Pfluge«; auch in vielen kleineren Erzählungen hat er dasselbe Thema bald in anmutig humoristischer, bald in ergreifender Weise variiert. Wenn er die inneren Kämpfe schildert, die durchgerungen werden müssen, um den Bruch mit der Vergangenheit, gleichviel wie trostlos diese war, zu vollziehen, so gemahnt es einen an den nach langer, langer Haft Befreiten, der seinen Kerker nicht verlassen mochte. Man vergesse nicht, daß ein religiöses Gesetz den Juden die Gemeinschaft mit Andersgläubigen verwehrt, daß so manche veraltete Vorschriften des Judentums mit den Anforderungen des modernen Lebens nicht $\mathrm{zu}$ vereinbaren sind. Wie könnten dabei schmerzliche Konflikte vermieden werden? Aller Starrsinn, den ein langer Druck in den Gemütern erzeugen kann, die tiefe Anhänglichkeit an die Satzungen, Sitten und Gebräuche, in denen sie bisher ihren einzigen Halt fanden, die ganze Macht des Traditionellen bäumt sich in ihnen noch einmal auf und erschwert den Übergang in die neue Ära. Vieles muß aufgegeben, vom Herzen losgerissen werden, um das Heimatrecht in dieser zu gewinnen. Mit gutem Grund betitelte Kompert seinen neuesten Roman »Zwischen Ruinen $«$. 
Die in Österreich eingeführte Notzivilehe ist es, die hier den Dichter beschäftigt. Das Gesetz gestattet die Ehe zwischen Christen und Juden nur unter der Bedingung, daß beide Teile sich als konfessionslos erklären eine harte Klausel, wenn man bedenkt, wie untrennbar bei den meisten gewisse religiöse Vorstellungen und Gemütsbewegungen mit allen ihren Jugendeindrücken und Jugenderinnerungen verwebt sind. Um sich dieses Auswegs ohne innerliches Widerstreben zu bedienen, muß man entweder auf jener geistigen Höhe stehen, von der aus betrachtet die Formen, in welche sich die Ahnung eines Göttlichen kleidet, nur äußerlich und deshalb gleichgiltig erscheinen, oder man muß frivol und oberflächlich genug sein, um überhaupt kein religiöses Bedürfnis zu verspüren. Die beiden Hauptpersonen des Kompertschen Romans sind von dem einen so entfernt wie von dem anderen. Der Weg zum Glück steht ihnen offen, ihr Herz drängt sie nach ihm hin, und schaudert doch wieder ängstlich zurück, wenn sie ihn betreten wollen.

Die Handlung begibt sich im nördlichen Böhmen, in einem jener Distrikte, in welchen die Rivalität des tschechischen und des deutschen Elements der religiösen Antipathie auch noch die politische beigesellt. Der katholische Tscheche haßt in dem Juden nicht nur den Andersgläubigen, sondern auch den fast durchgängig zur deutschen Partei Gehörigen. In einem Städtchen dieser Gegend lebt der wohlhabende jüdische Fabrikant Jonathan Falck. Er ist mit einer Frau seines Glaubens verheiratet. Ihre Ehe gilt für glücklich, weil die beiden Gatten friedlich nebeneinander 66 hinleben; niemand denkt daran, daß zum Glück einer Ehe unendlich mehr erforderlich ist. Jonathan und Bella passen nicht zueinander. In ihm ist vor allem das Gefühlsleben mächtig, während ein scharfer überlegener Verstand der Grundzug ihres Wesens ist. Ohne es zu wollen, verletzt sie ihren Mann bald durch den geistigen Hochmut, der sie, die in einer gebildeteren, aufgeklärteren Gemeinde aufgewachsen ist, den Verkehr mit ihrer jetzigen Umgebung meiden läßt, bald durch ihre Gleichgiltigkeit gegen die rituellen Vorschriften. Nicht als ob er ein Zelot wäre; er ist nur einer jener Menschen, die gern dem geringfügigsten eine Bedeutung unterschieben, um ihrer Überfülle von Pietät Abfluß zu verschaffen. Um die Dogmen kümmert er sich wenig; hingegen ist es ihm hochwichtig, daß »König Sabbath « mit den gebührenden Ehren empfangen und alles in der Weise seiner orthodoxen Eltern gehalten werde. Der Zufall führt Dorothea, die halberwachsene Tochter eines armen deutschen Webers, in diesen Familienkreis, und bald erlebt Jonathan die Genugtuung, die zahllosen Vor- 
schriften des jüdischen Rituals in seinem Hause pünktlich befolgt zu sehen. Und eine Christin ist es, welche dieses Wunder bewirkt. Die Erklärung liegt in der tiefen Frömmigkeit, welche Dorotheen angeboren ist, und sie in jeder Religion etwas heiliges und ehrwürdiges erkennen läßt. Dieser Zug ihres Charakters macht sie Jonathan nicht minder wert als ihre leidenschaftliche Zärtlichkeit für sein Söhnchen. Ahnungslos erwidert Dorothea seine Neigung; beide lieben einander ohne es sich selbst zu gestehen. Bellas früher Tod scheint eine Lösung bringen zu wollen, führt aber nur noch größeres Wirrsal herbei. Alles was bisher geschah, ist nur als Exposition zu betrachten; erst jetzt beginnt das eigentliche Drama, das harte Ringen in zwei Menschenseelen, die ihre heiße Sehnsucht nach dem Glück, das ihnen verheißend winkt, nicht in Einklang mit ihrem Gewissen zu bringen vermögen. Daß dieser Kampf in so eigenartigen Gemütern ein schwerer, bedrängnisvoller sein muß, braucht nicht erst gesagt zu werden. Seine Mühen und Qualen hier wiederzugeben, seinen Ausgang mitzuteilen, würde zu weit führen, und könnte überdies nur auf Kosten der Spannung geschehen, mit welcher die Leser des Romans seinem Gange folgen werden.

Von mancher Seite her dürfte dem Verfasser der Vorwurf gemacht werden, daß uns seine eigene Ansicht über die Institution, die ihm das Motiv zu seinem Werke gab, zweifelhaft bleibt. Mit Recht könnte er jedoch darauf erwidern: daß jede Polemik ganz außerhalb seiner Absichten lag; daß er nicht Gesetze verbessern, sondern nur die Konflikte, die hervorzurufen sie geeignet sind, schildern wollte; daß überhaupt ein Kunstwerk nur darzustellen, nicht zu beweisen hat. Mehr Grund möchte das Bedenken haben ob der Autor nicht besser getan hätte, seinen Helden mit etwas mehr Männlichkeit und Willenskraft auszustatten. Der Kampf, der hier in einer Menschenbrust tobt, wäre ergreifender, wenn ein starkes Herz ihn zu bestehen hätte, und schließlich aus eigener Erkenntnis das Richtige wählte. Jonathans Schwäche, die ihn jedem Einflusse preisgibt, vermindert unsere Teilnahme für ihn. Fast möchte man es nur als einen glücklichen Zufall betrachten, daß das gute Prinzip, das durch die alte blinde Lehrerswitwe Veile Oberländer vertreten wird, den Sieg davonträgt. Bei einem Menschen, der so ganz der Selbstbestimmung ermangelt wie Jonathan, könnte ebenso zufällig der haßvolle Wahn, der wilde Fanatismus, dessen Repräsentant sein halbtoter Bruder ist, die Oberhand gewinnen. Da es jedoch in der Wirklichkeit genug ähnliche Charaktere gibt, so hat man kaum die Befugnis mit dem Autor darüber zu rechten, daß er in seinem Helden eine dieser weichen, jedem Anstoße folgenden, Naturen darstellte. 
Was die Ausführung betrifft, so läßt sich kein Tadel dagegen erheben; die Gestalt ist wahr und in allen Schwankungen fein empfunden. Dasselbe gilt von Dorothea, deren Wesen mit reizenden Zügen bedacht ist. Merkwürdigerweise fällt die Rolle, welche sonst das männliche Geschlecht für sich in Anspruch zu nehmen pflegt, in diesem Roman den Frauen zu: von ihrer Einsicht, ihrem hellen Verstand geleitet, tut Bella was sie vermag, um den Moder der Vergangenheit zu beseitigen; von ihrem warmen treuen Herzen erleuchtet, lernt Veile die Vorurteile, in denen sie ergraut ist, mit Füßen treten. Hier sind die Frauen die Verkünderinnen der neuen Zeit, während die Männer zäh am Überkommenen hangen. Mit dem Fanatiker, der nach einem zügellosen Leben den Glauben als letzten Anker verzweifelnd erfaßt, hat Kompert so recht einen Schuß ins Schwarze getan. Er ist eine ebenso wahre wie durchaus originelle Figur, und die Erzählung, in der er von seiner wüsten Vergangenheit berichtet, ist allein schon ein Meisterwerk. Nicht so unbedingt, wie die feine lebendige Individualisierung jüdischer Typen, läßt sich die Führung der Handlung rühmen, die mitunter stocken, mitunter über wichtige Phasen zu rasch hinweg eilt. Der Gehalt des Romans ist jedoch zu bedeutend, als daß einzelne Schwächen der Komposition seinen Wert und seinen Erfolg erheblich beeinträchtigen könnten; durch den Gedankenreichtum, dem man überall begegnet, die Wahrheit der Charaktere, die schöne Wärme der Empfindung werden sie mehr als aufgewogen. Der Roman wird um so sicherer durchdringen, als er mit literarischer Trefflichkeit den Vorzug verbindet, ein lebenatmendes Kulturbild zu sein.

In dem Buche der Freiin Marie v. Ebner-Eschenbach begegnet man einem Erzählertalent, das mit offenem Sinn und reger Empfänglichkeit 70 für die Erscheinungen der Welt die Tiefe der Auffassung verbindet, ohne welche sie der inneren Begründung entbehren. Unter den fünf Erzählungen, welche der Band enthält, ist nicht eine, die nicht ein ungewöhnliches Maß von Geist, poetischer Kraft, umfassender Weltkenntnis bekundete, und nur eine in welcher Form und Inhalt sich nicht vollkommen decken. Die erste derselben, »Ein Spätgeborener «, entrollt uns die Schicksale eines Idealisten, den sein Unstern in einer Zeit geboren werden ließ, die mit allen Idealen gründlich aufgeräumt und für jede schwärmerische Regung nur ein mitleidiges Lächeln hat. Vor hundert Jahren, in Höltys Tagen, hätte Andreas Muth gleichgestimmte Seelen finden können; in der nur auf Gewinn und Genuß erpichten Gegenwart stände er allein, wenn nicht ein armer Volksschullehrer die Freundschaft, die er für Andreas empfindet, 
auch auf dessen poetische Schöpfungen übertrüge. Die Schilderung dieses Verhältnisses und der milden Heiterkeit, die ein reiner Sinn, ein demütig sich bescheidendes Herz über ein scheinbar sonnenloses Leben ergießen, ist von rührender Schönheit. Arm, von den meisten übersehen, für andere ein Gegenstand des Spottes, ist Andreas dennoch weit entfernt, sich unglücklich zu fühlen, solang' es ihm gegönnt bleibt, sich in seiner Einsamkeit mit geliebten Traumgestalten zu umgeben und den Zusammenstoß mit der rauhen Wirklichkeit zu vermeiden. Unerwartete Ereignisse reißen ihn aus diesem trauten Dämmerzustande. Der Schüchterne, in sich Versunkene wird in die Öffentlichkeit hinausgezerrt, und soll sich in einer Welt behaupten, die ihn so wenig versteht, wie er sie. Die Zeichnung dieses Charakters, die Schilderung der namenlosen Bedrängnis, die eine so zart besaitete Natur im Kampfe mit den niederen Mächten des Lebens empfinden muß, gehören zu dem besten, was die neue Novellistik aufzuweisen hat. Mit künstlerischer Einsicht hat die Verfasserin die Klippen vermieden, an denen die Darstellung eines solchen Seelenzustandes leicht hätte scheitern können. Ihr Held ist weder ein verkanntes Genie noch ein Phantast, sondern ein ungewöhnlich rein gestimmtes Gemüt, das instinktmäßig die höchste und reinste Sphäre aufsucht. Das Maß seines poetischen Talents kümmert uns wenig; er selbst ist ein Gedicht, wie es der Natur nur selten gelingt. Seine Schüchternheit, sein unbeholfenes Wesen hindern ihn nicht, mit festem Mannesmut das Recht und den Ruf anderer zu vertreten; unerschrocken gibt er der Wahrheit die Ehre, gleichviel, wie teuer ihm dieses Beginnen zu stehen kommt. Die Zeichnung des ganzen Charakters atmet einen liebenswürdigen, von leiser Wehmut überflogenen Humor. Denn auch diese, bei Frauen so seltene Gabe, ist der Verfasserin zuteil geworden, und kommt in manchen Figuren, häufig mit einem satirischen Beigeschmack, zur vollen Geltung, z.B. in dem vom Gefühl seiner Würde durchdrungenen Bureauchef, dem skandalsüchtigen Journalisten Salmeyer und den Kollegen Andreas', die nach Art der Flachköpfe dasjenige verlachen, was sie nicht zu begreifen imstande sind. Das dramatische Talent, von dem Freiin v. Ebner schon früher Proben abgelegt hat, kommt ihr als Erzählerin gar sehr zu statten. Es betätigt sich in der Plastik ihrer Gestalten, in dem Geschick, womit sie die Personen perspektivisch gruppiert, und in dem fein individualisierenden Dialog.

Die zweite Erzählung "Chlodwig«, beweist, daß die Verfasserin für die Darstellung starker, leidenschaftlicher Charaktere ebenso befähigt ist wie für die mimosenhaften Gemüter vom Schlag Andreas'. Das tiefe psycho- 
logische Interesse, das sie erweckt, und die frappante Schlußwendung machen diese Erzählung zur vorzüglichsten der Sammlung. Die Eigentümlichkeit der Figuren, der fatalistische, weil in inneren Notwendigkeiten begründete, Gang der Handlung, die strenge Knappheit der Form, die objektive, scheinbar kunstlose Art des Erzählens, verraten ein eifriges Studium Mérimées und Turgenjeffs, der beiden Meister der Novelle. Heines Vers »Verfehlte Lieb', verfehltes Leben« dürfte der genannten Erzählung als Motto voranstehen. Sie zeigt uns, welche moralischen Krüppel anerzogene Vorurteile ausbilden, wie sie das Herz zu lähmen und dem Willen eine seiner natürlichen Richtung entgegengesetzte zu geben vermögen. Was von dem ursprünglichen Menschenbilde dann noch übrig bleibt, ist nur ein blutloser Schemen, und wehe dem Verblendeten, der vermeint, frisches Leben in ihm wecken zu können. Mit großer Kunst hat die Verfasserin bei der Zeichnung eines im innersten Nerv beschädigten Frauencharakters das Anwidernde fernzuhalten gewußt. Vielleicht wäre Hedwig unter anderen Verhältnissen ein liebendes Weib geworden; so wie sie ist, erblicken wir in ihr das traurige Resultat einer törichten Erziehung, das Opfer der vorurteilsvollen Umgebung, in der sie stets gelebt hat. Neben den trefflich ausgeführten Hauptcharakteren verdient die meisterhaft skizzierte Figur des Majors eine besondere Erwähnung. Er steht außerhalb der Handlung, nichts geschieht durch ihn, wir lernen ihn durch die lakonischen Äußerungen kennen, mit welchen er die Erzählung Chlodwigs unterbricht; diese sind so überaus bezeichnend, daß uns in ihnen das ganze Wesen des Mannes, und der Stand, dem er angehört, deutlich werden. Er ist der in einen Offiziersrock gesteckte Durchschnittsmensch.

Schärfe der Zeichnung und frische Lokalfärbung sind überhaupt sehr wesentliche Vorzüge dieser Erzählungen. Man kann nicht sagen, daß sie Bilder österreichischer Verhältnisse sind, dieselben Begebenheiten wären auch anderswo möglich, um so treffender schildern sie aber die dem 74 österreichischen Stamme eigene Anschauungs- und Gefühlsweise. »Die erste Beichte « läßt uns einen Blick in das Seelenleben eines ungewöhnlich begabten Kindes tun, das von den Seinigen zwar geliebt, aber nicht verstanden, in religiöser Exaltation die Befriedigung seines schwärmerischen Dranges sucht. An der kleinen Clary ist vor allem die vollkommene Naivetät zu rühmen, welche die Verfasserin ihr zu bewahren wußte. In Pater Joseph, dem die Aufgabe zuteil wird, dieses sich selbst unklare, schwer bedrängte Herz auf die Bahn richtigen Empfindens zu leiten und den anderen $\mathrm{zu}$ besserer Einsicht in das Wesen des eigenartigen Kindes zu 
verhelfen, lernen wir eine, trotz ihrer Schlichtheit, ehrfurchtgebietende Priestergestalt kennen. Clarys Vater und ihre Großmutter sind wahre Kabinettsstücke: er gutmütig, von redlichem Willen seine Pflicht zu tun erfüllt, aber unfähig zu begreifen, worin sie eigentlich bestehe, und eigenwillig, wie die Beschränktheit zu sein pflegt; sie edel, großsinnig, aber zu müde, zu sehr der Ruhe bedürftig, um auf die heftigen Empfindungen eines Kindes teilnehmend einzugehen. Das Ganze ist ein reizendes und rührendes Seelengemälde, von dem wohlweislich jeder frömmelnde Zug ausgeschlossen blieb.

Die kleine Erzählung »Die Großmutter« besteht eigentlich nur aus einer Szene, aber diese genügt, um uns die ganze Vergangenheit der unglücklichen alten Frau überblicken zu lassen, deren in harter Arbeit und steter Sorge verbrachtes Leben nur einen Lichtpunkt hatte: ihren Enkel, den Sohn ihrer mißratenen, elend verkommenen Tochter. Auch ihn muß sie verlieren; in der Leichenkammer des Spitals findet sie unter den zufällig Verunglückten den vermißten Liebling wieder. Viele werden es unbegreiflich, ja empörend finden, daß sie in diesem entsetzlichen Augenblick an die Verwertung der Kleider des Toten denken mag. Die glücklicher Gestellten wissen aber nichts von der harten Kruste, die langes Elend um das Herz des Menschen legt. Unter ihr mag es seine volle Wärme, seine ganze Leidensfähigkeit bewahren, aber schön empfinden, seinem Schmerz einen verklärten Ausdruck geben, kann es nicht mehr. Der bitterste Fluch der Armut liegt in dem Zwang, das Gefühl der Sorge um das tägliche Brot zu unterordnen; ihr schwerer Druck macht die Seele endlich ebenso schwielig wie die Hände.

Die fünfte und letzte Erzählung, »Ein Edelmann«, ist in ihrem Gedankeninhalt nach vielleicht die bedeutendste, steht jedoch, als Kunstwerk betrachtet, nicht auf der gleichen Höhe mit ihren Vorgängerinnen. Sie leidet an den Folgen, die eine Verrückung des natürlichen Schwerpunkts nach sich zieht. Diesen Schwerpunkt bildet hier Gräfin Beate, sie müßte daher die Hauptfigur sein. Selbst dann bliebe es noch fraglich, ob der enge Rahmen einer Erzählung für die Ausführung eines solchen Charakterbildes ausreichend wäre. Der Stoff hätte $\mathrm{zu}$ einem Roman gestaltet werden sollen, denn nur die breite Behandlung, welche dieser gestattet, ja fordert, hätte eine überzeugende Motivierung der Untaten ermöglicht, zu welchen Beate sich hinreißen läßt. Um zu begreifen, wie der Hochmut an einer Seele nach und nach alle menschlichen Regungen zu ersticken vermag, müßten wir ihren Entwicklungsgang genau kennen lernen. Weil 
die Prämissen fehlen, die uns eine solche Erscheinung erklären sollten, macht sie uns den Eindruck des Gespenstischen, Spukhaften. Ist aber diese Erzählung, trotz mancher großen Schönheiten, die sie enthält, nicht tadellos, so gewinnt sie nichtsdestoweniger eine schwerwiegende Bedeutung durch den geistvollen Ernst, womit darin eine soziale Frage erörtert wird die Frage: ob, unter den gänzlich veränderten Verhältnissen, welche die Neuzeit hergestellt hat, der Geburtsadel sich wird behaupten können. Ich tue wohl am besten, die Ansicht der Verfasserin mit den Worten wiederzugeben, welche sie der edelsten Gestalt ihrer Erzählung in den Mund legt. Wolfram, der, von seiner Überzeugung dazu bestimmt, sich seines Grafentitels begeben hat, äußert gegen seinen Sohn Leo:

»Solange das Feudalwesen sich in seiner Kraft behaupten konnte, hatte es ein Recht, sich zu behaupten. Diese Kraft büßte der Adel dadurch ein, daß er versäumte, sie auf edle und gemeinnützige Ziele zu richten. Er erfuhr die Konsequenz ewiger sittlicher Gesetze, indem er mit dem Rechte zu bestehen auch die Möglichkeit zu bestehen verlor.«

Für den Fall, daß Leo einst aufgefordert werden sollte, den Rang und die Güter anzutreten, auf welche sein Vater verzichtet hat, läßt Wolfram ihm freie Wahl, nach seiner eigenen Erkenntnis zu handeln, nur Ganzheit im Wollen und Tun macht er ihm zur Pflicht: "Sei als Graf Tannberg kein Fabrikant, nenne dich nicht Graf Tannberg, wenn du ein Fabrikant bist. Das eine schließt das andere aus. Der ehrenwerteste Kaufmann verfolgt materielle, der Edelmann, im wahren Sinne, ideale Zwecke. In dem Augenblick, wo der letztere vergißt, daß in ihnen, und in ihnen allein, seine Kraft wurzelt, hat er sich als Edelmann aufgegeben."

Ich habe dem Buch die eingehende Würdigung gezollt, die es, vermöge seines geistigen Gehalts und seines poetischen Reizes, beanspruchen darf. Meiner Empfindung, meinem Urteil nach gehört es zu jenen Büchern, die ihrem Verfasser in jedem Leser einen Freund erwerben.

\section{Božena}

Es mögen jetzt anderthalb Jahre her sein, daß, gleichfalls im Cottaschen 78 Verlag, ein Band Erzählungen von derselben Verfasserin erschien und alsbald die Aufmerksamkeit des gebildeten Publikums auf sich lenkte. Was der bis dahin in Deutschland wenig bekannten Schriftstellerin zu diesem raschen Erfolg verhalf, war nicht nur ihre überaus reizende und anmutige Erzählergabe, es war vor allem die überzeugende Lebenswahrheit 
ihrer Gestalten, das warme Leben, das in ihnen pulsierte. Der Leser mußte ihnen seine Teilnahme schenken, denn als Wesen seines Stammes, nicht als blutlose Schemen, traten sie vor ihn hin: die einen lächelnd, oder ein Lächeln hervorrufend, die andern mit trüb umflortem Blick, von der Last des Unglücks oder der Schuld gebeugt, aber alle ohne Ausnahme wahre, wirkliche Menschen, mit den Vorzügen und den Fehlern, dem Adel und der Schwäche ausgestattet, die unseres Geschlechtes Erbteil sind. Und wie die Zeichnung der Charaktere einen seltenen Scharfblick für die verschiedenartigsten Seelenzustände verriet, so bekundete das Gefüge der Handlung, die Art und Weise wie die äußeren Begebenheiten motiviert und herbeigeführt waren, eine große Weltkenntnis, ein starkes Gefühl für die Wirklichkeit und infolgedessen ein reges Verständnis für die Verhältnisse der Gegenwart, für die Forderungen, die sie stellt, die inneren und äußeren Konflikte, die sie heraufbeschwört. Wer da Augen hatte um zu sehen, der erkannte in diesen Erzählungen das Walten eines ebenso gebildeten wie begabten Geistes, eines Gemütes, dem nichts menschliches fremd geblieben ist, eines Talents, dem die Fähigkeit ward, die der Wirklichkeit, wie das Gold dem Erz, eingesprengte Poesie ans Licht zu fördern. Das erklärt den Beifall, den sie fanden, das berechtigte jeden, der sich an ihnen erfreute, den ferneren Leistungen der Verfasserin mit hochgespannten Erwartungen entgegen zu sehen.

Diese Erwartungen wurden nicht getäuscht, sondern weit eher übertroffen. Alle Vorzüge, welche das frühere Werk Frau v. Ebners dem Publikum lieb und wert machten, finden sich in ihrem letzterschienenen, der einen Band füllenden Erzählungen »Božena", wieder, aber eine fortschreitende Reife der Einsicht und eine größere literarische Erfahrung haben dieselben zu noch freierer Entwicklung gebracht. Wie eine Singstimme durch fortgesetzte Übung an Schönheit und Rundung des Tones gewinnt, so hat das Talent der Verfasserin, durch den Fleiß, der ihr zur Seite steht, zusehends an Umfang und Tragweite gewonnen. Ich meine nicht den Fleiß, der darin besteht, tagtäglich so und so viel Bogen vollzuschreiben - den haben nur gar zu viele! - sondern die künstlerische Gewissenhaftigkeit, die alles nur leidlich Gute als ungenügend verwirft, die, statt sich mit einem à peu près zu begnügen, an einem Werk unverdrossen schafft und feilt, bis sie es von der unscheinbarsten Makel befreit und nach bestem Erkennen und Vermögen alle seine Teile harmonisch zusammengestimmt hat. Dieser Fleiß, diese unnachsichtige Strenge gegen sich selbst, diese Hingebung, die keine Mühe und Arbeit scheut, wenn sie dem im Entstehen 
begriffenen Werke zu gute kommen können, sie sind es, die den Künstler vom Dilettanten unterscheiden, wenn auch die ursprünglichen Anlagen beider sich zufällig die Wage halten sollten. Man muß in der Kunst sein höchstes Lebensglück erblicken, wenn man den Mut finden soll, ihr die Opfer zu bringen, die sie verlangt. Das wissen die Dilettanten nicht, die da meinen mit ihr tändeln zu dürfen, und noch weniger ahnen es die Handwerker, die sie als Gewerbe betreiben.

Die Erzählung bewegt sich in einfachen Verhältnissen; ihr bescheidener Schauplatz ist teils eine mährische Landstadt, teils ein in der Nähe desselben gelegenes gräfliches Schloß. Die Menschen, die sie uns vorführt, stehen, die großartig angelegte Hauptfigur ausgenommen, auf einem Niveau mit vielen anderen Erdenkindern, und eben so wenig Anspruch auf Absonderlichkeit haben die Begebenheiten, von denen sie berichtet. Worin liegt nun der Zauber, mit dem sie uns dennoch gefangen hält? Wie kommt es, daß wir den Lebenswegen dieser Menschen, an denen wir, wenn wir ihnen in der Wirklichkeit begegneten, vielleicht gleichgiltig vorübergehen würden, mit gespanntem Interesse folgen müssen? Es kommt daher, daß 81 wir sie hier bis zur innersten Herzensfaser kennen lernen und aus ihrem Charakter heraus ihr Tun und Lassen, ihr ganzes Schicksal mit unabweislicher Notwendigkeit sich entwickeln sehen. Die Wirklichkeit mit ihren tausend Zufälligkeiten ist gleichsam ein Nebel, der unseren geistigen Blick beschränkt, beirrt und ihn hindert, die Erscheinungen in ihrer Totalität aufzufassen. Die Poesie hat den Beruf, ihn mit ihrem mächtigen Odem $\mathrm{zu}$ zerstreuen und aus dem wüsten Chaos eine von ethischen Gesetzen beherrschte Welt zu schaffen.

Eine solche Welt erschließt sich uns in diesem Buch; eine allerdings eng begrenzte, aber festgefügte, abgeklärte, dem Spiel des Zufalls entrückte Welt. So klein sie ist, hat sie doch Raum genug für die Entwicklung der verschiedenartigsten Charaktere, für das Gewoge edler und niedriger Leidenschaften, Raum genug für Lust und Weh, Schuld und Sühnung. Die Menschen, die sie bevölkern, haben Blut in den Adern und sicheren Boden unter den Füßen. In der Führung ihrer Schicksale ist wohl ein leitender Gedanke - und wer möchte einen solchen vermissen? - aber keine Willkür und keine Absichtlichkeit bemerkbar. Mit selbstständigem Leben ausgestattet, werden sie nur von jener geheimnisvollen Kraft bestimmt, gelenkt, die, man mag sie Willen, Instinkt, angeborenen Charakter nennen, des Menschen tiefstes, unveränderliches Wesen ausmacht und 82 sein Handeln bedingt. Die Kraft, mit welcher der Grundzug ihres Wesens 
hervorgehoben ist, erhebt sie zu Typen, tausend feine, eigentümliche Züge verleihen ihnen den Reiz, der in der Kunst wie im Leben nur die individuelle Besonderheit ausübt. Es wird uns nicht gesagt, wes Geisteskinder sie sind, noch wissen sie es selbst, um so klarer wird es jedoch dem Leser durch jede ihrer Handlungen, ja durch jedes Wort, das aus ihrem Munde geht. Die Verfasserin läßt sich weder auf eine Analyse der verschiedenen Charaktere ein, noch befaßt sie sich viel mit der Beschreibung des Äußeren der uns vorgeführten Personen; dennoch blicken wir ihnen bis auf der Seele Grund, dennoch sehen wir sie in voller Leibhaftigkeit vor uns stehen und können sie uns nur in dieser, keiner anderen Gestalt denken. Die Phantasie des Lesers so mächtig anzuregen, daß sie dichterischen Gebilden eine schier greifbare Form geben muß, ist nicht bloß das Vorrecht eines großen Talents; es setzt auch jene Beherrschung aller künstlerischen Mittel voraus, die der natürlichen Begabung erst $\mathrm{zu}$ ihrer vollen freien Machtentfaltung verhilft.

Selbstverständlich bildet die Gestalt, die der Erzählung den Namen gibt, den Mittelpunkt derselben; an Leib und Seele ragt sie über alle anderen hinaus. Sie ist nur eine Dienstmagd, aber die Natur hat ihr eine jener Seelen gegeben, von deren Reinheit, Treue und selbstlosem Opfermut sich selbst diejenigen, die keinen sittlichen Maßstab für solche Vorzüge haben, unwillkürlich das Knie beugen müssen. Wahrheit und Gerechtigkeit sind ihr Lebensodem; unter ihrem Zeichen kämpft und siegt sie. Man weiß kaum, was an dieser Figur mehr zu preisen ist, ob der grandiose Entwurf, ob die bei aller Vollendung so schlichte Ausführung, die derselben ihre vollkommene Naivetät und Unbefangenheit wahrt.

Nur flüchtig will ich den Gang der Erzählung in ihrer ersten Hälfte skizzieren. Wir lernen Božena im Hause des reichen Weinhändlers Leopold Heißenstein kennen. Jahre und Jahre hindurch findet ihr starkes, heißes Herz sein volles Genüge in der Liebe zu dem ihrer Pflege anvertrauten Kinde, dem von einer ränkevollen, nur auf das Wohl des eigenen Sprößlings bedachten Stiefmutter Schlimmes droht. Božena, in ihrem Liebling fortwährend gekränkt, will nicht länger Zeugin solchen schreienden Unrechts sein. Es kommt zwischen ihr und Frau Nannette zu einer heftigen Szene. Nachdem sie ihrer Entrüstung Luft gemacht hat, ist sie im Begriff das Haus für immer zu verlassen - da hängt sich Rosa an ihre Kleider, da fleht Rosa: »Geh nicht, geh nicht! « und um die ganze Kraft der Gewaltigen ist es getan. Sie bleibt nicht nur, sie erniedrigt sich zu der Bitte, bleiben zu dürfen, die ihr Frau Nannette im wohlverstandenen eigenen 
Interesse bewilligt, natürlich nicht ohne sie es durch tausend Nadelstiche 84 entgelten zu lassen. In Boženas Innern kocht und gärt es; Sanftmut und Fügsamkeit sind durchaus nicht ihre Haupttugenden, aber sie hat es ein für allemal aufgegeben, die Fesseln zu zersprengen, in welchen die Liebe $\mathrm{zu}$ dem nun schon herangewachsenen Mädchen sie gefangen hält. Sie kann, sie darf Rosa nicht verlassen. Zu all dem Drangsal gesellt sich noch ein neues Wirrnis. Božena ist dreißig Jahre alt geworden, ohne das Mannsvolk der geringsten Aufmerksamkeit zu würdigen: plötzlich faßt sie eine heftige Leidenschaft für einen jungen Menschen, dessen schönes Äußere einer erbärmlichen Seele zur Hülle dient. Sie täuscht sich nicht über seinen Unwert, sie verachtet sich ob ihrer Liebe zu ihm, und vermag dennoch nicht sie aus ihrem Herzen zu reißen. Bernhard hat zwar kein Herz, doch immerhin hat er sinnliche Begierden; stürmisch wirbt er um ihre Gunst. Sie erliegt der Versuchung: in stiller Nacht schleicht sie heimlich zu ihm. Die Strafe für ihren Fehltritt ereilt sie unmittelbar nach demselben: in derselben Nacht ist Rosa mit ihrem Geliebten, dem Leutnant Wilhelm v. Fehse, aus dem väterlichen Haus entflohen. Verzweifelnd muß Božena sich anklagen, daß nur ihre Abwesenheit diese Flucht ermöglicht hat. Dieser Schlag mitten ins Herz hinein, bricht den bösen Zauber, der so lange ihre Sinne und Gedanken bestrickt hielt. Für alle Zukunft sagt sie sich von Bernhard los; ihr Leben hat fortan keinen anderen Zweck als 85 den, das Unheil gut zu machen, das sie, freilich ohne Wissen und Willen, herbeiführen half. Sie folgt Rosa, die inzwischen Fehses Frau geworden ist, teilt Mühsal und Entbehrung mit den Menschen, die sie liebt, und verwendet ihre Ersparnisse zur Unterstützung des ärmlichen Haushaltes. Eine Machination Frau Nannettens hat nämlich den gerechten Zorn Heißensteins bis zu unversöhnlichem Groll aufgestachelt; alle Versuche Rosas, die Verzeihung ihres Vaters zu erlangen, bleiben erfolglos. Mit sich und der Welt zerfallen, streicht er ihren Namen aus seinem Testament und setzt Regula, seine Tochter aus zweiter Ehe, zur Erbin seines ganzen großen Vermögens ein. Aber die Rache, die er an Rosa nimmt, wendet sich gegen ihn selbst; ohne sich's einzugestehen, ja ohne es selbst zu wissen, liebt er die ungehorsame Tochter, die er zu hassen glaubt, und kann ihren Verlust nicht verwinden. Er siecht dahin an dem unheilbaren Riß, der durch sein inneres Leben geht. Nun drängen sich die Ereignisse. Gram und Sorge haben Rosas Gesundheit unterwühlt, sie stirbt im fernen Siebenbürgen. Bald darauf fällt Fehse im Kampfe gegen die ungarische Revolution. Božena, die Vielgetreue, bringt Röschen, das einzige Kind der nun 
im Grabe Wiedervereinten, auf ihren Armen in die Heimat zurück, die Mühen und Gefahren der weiten Wanderung nicht achtend. Als sie das Haus betritt, liegt Heißenstein im Sterben; die Nachricht von Rosas Tod hat ihm das Herz gebrochen. Sein letzter Blick ruht wehmut- und liebevoll auf dem verwaisten Enkelkinde, sein letztes Wort schärft Regula ein, schwesterlich für die Kleine zu sorgen. Fräulein Regula ist jedoch sehr weit entfernt, dieses Gebot als bindend zu betrachten. Ein Inbegriff von Selbstsucht, Eitelkeit und Herzenskälte, verbannt sie das Kind in die Gesindestube, und wie einst Rosa, findet nun auch deren Tochter nur bei Božena und dem alten Kommis Weberlein Liebe und Zärtlichkeit. Boženas ganzes Sinnen und Trachten ist darauf gerichtet, Röschen in die von deren Mutter verwirkten Rechte einzusetzen, aber wie dieses Ziel ihres heißesten Wunsches erreichen? Daß Fräulein Regula nie gutwillig die Hand dazu bieten wird, ist nur zu gewiß. Da, während Božena unermüdlich nach Mitteln und Wegen späht, bricht die schwerste Prüfung über sie herein. Bernhard, den sie seither nicht wieder gesehen hat, kehrt, ein jetzt auch äußerlich ganz verkommenes Subjekt, nach langer Abwesenheit in die Stadt zurück. Er drängt sich in eine Gesellschaft, in welcher Božena anwesend ist und beschimpft diese öffentlich, indem er sie sein früheres Liebchen nennt. Die gute Meinung, die man von ihr hat, ist so fest gewurzelt, daß es nur eines Wortes aus ihrem Munde bedurfte, um die ganze Anschuldigung als Verleumdung oder als das sinnlose Geschwätz eines Halbbetrunkenen hinzustellen. Aber dieses Wort wäre eine Lüge, und Božena kann nicht lügen. Bernhards Behauptung hat eine allgemeine Entrüstung hervorgerufen, man will ihn aus dem Saal entfernen; er aber tritt frech vor Božena hin, und fordert sie auf zu erklären, ob er wahr gesprochen habe, oder nicht. »Wahr!« stammelte sie mit gesenktem Haupte, vor Scham und Qual vergehend, doch selbst im Augenblick der entsetzlichsten Bedrängnis sich selbst getreu. Nun scheint alles verloren: sie darf nicht länger hoffen, den geringsten Einfluß zugunsten ihres Schützlings auf Regula auszuüben, vielmehr muß sie froh sein, nach jenem Auftritt im Hause noch geduldet zu werden. Jetzt aber beginnt die Wirkung eines sittlichen Gesetzes. Die Katastrophe, die so ganz danach angetan schien, Božena in den Staub zu treten, erhöht sie, nicht nur vor dem unsichtbaren Richter, sondern auch in den Augen der Menschen. Bewußt oder unbewußt fühlen alle, welche Zeugen jenes erschütternden Vorganges waren, wie wenig ein einzelner Fehltritt zu bedeuten hat, wenn er durch solche Reinheit des innersten Wesens, durch solche unverbrüchliche 
Wahrhaftigkeit mehr als aufgewogen wird. Die Achtung, die man ihr früher zollte, wird zur Verehrung, man weiß, daß jedes ihrer Worte Eideskraft hat. Diese allgemein verbreitete Überzeugung, die moralische Autorität, die sie Božena verleiht, geben dieser Mittel an die Hand, ihre Lebensaufgabe zu erfüllen, nämlich an Röschen gut zu machen, was sie an deren Mutter verschuldet zu haben glaubt. In welcher Weise dies geschieht, auf welchem Wege Regula dahin gebracht wird, dem Mädchen sein Recht widerfahren zu lassen, will ich dem Leser nicht verraten, das Buch selbst mag ihm Aufschluß darüber geben. Er wird finden, daß das Interesse, das gleich der Anfang der Erzählung erweckt, sich fortwährend steigert, bis der mit psychologischer Meisterschaft herbeigeführte Schluß es voll und ganz befriedigt.

Selten wird man in einem Werke von verhältnismäßig so geringem Umfang - man erinnere sich nur an die vielbändigen Romane, die uns jahraus jahrein beschert werden! - einer solchen Fülle von originell erfundenen und mit strenger Konsequenz durchgeführten Charakteren begegnen. Wir treffen hier Menschen von den verschiedensten Gemütsarten, aus den verschiedensten Gesellschaftsklassen, und nicht bei einem von ihnen vermissen wir die bestimmt ausgeprägte individuelle Physiognomie. Die Hauptfiguren sind mit weiser, nie kleinlicher und peinlicher Sorgfalt ausgeführt. Bei Nebenpersonen genügen der Verfasserin wenige Striche, um uns das oft von humoristischen Streiflichtern umspielte Bild vors Auge zu zaubern. Es geht kaum an, aus einer Reihe von Gestalten, die alle von gleichem Lebensgefühl durchströmt, alle gleich wahr und vortrefflich sind, die eine oder die andere besonders hervorzuheben. Man hat ja aber selbst unter Brüdern noch immer seine besonderen Lieblinge und so mag ich wohl gestehen, daß der alte Graf Rondsperg der meinige ist. In ihm zeigt sich uns der vollendete Typus eines österreichischen Kavaliers aus vormärzlicher Zeit. Welche Mischung von Gutmütigkeit und naivem Egoismus, von liebenswürdiger Bonhomie und aristokratischem Selbstgefühl! Wie wahrhaft adelig ist sein Gemüt und wie unfähig ist er doch den Unterschied von Recht und Vorrecht, die Notwendigkeit der Wandlungen, die um ihn her vorgehen, ja nur seine eigene wirkliche Lage zu begreifen! Und der Kommis Weberlein, das gnomenhafte Männchen mit dem reinen, edlen Herzen, der konservativen Gesinnung und den wunderlichen militärischen Velleitäten! Beide sind prächtige Kabinettsstücke voll überzeugender Wahrheit und köstlichen Humors. 
Ein wesentlicher Reiz des Werkes beruht auf der streng eingehaltenen Lokalfärbung. Die Charaktere selbst sind so echt menschliche, daß sie überall vorkommen könnten; aber ihre Weise, sich in gewissen Äußerlichkeiten zu betätigen, sich zu geben, ist spezifisch österreichisch. Ebenso wären die Verhältnisse, in denen sich die handelnden Personen bewegen, an jedem beliebigen Orte denkbar und möglich, doch erinnern uns tausend kleine Nuancen derselben beständig an den besonderen Boden, auf dem sie sich entwickelt haben. Indem sie die Eigenart eines Volksstammes und seine von ihr bedingten Lebensformen richtig betont, gewinnt die Erzählung an Frische, Anschaulichkeit und plastischer Rundung.

Der Stil des Buches ist vortrefflich; das will sagen: klar, einfach und edel, im Dialog ganz dramatisch bewegt, durchwegs von der größten Präzision des Ausdruckes in den ernsten wie in den humoristischen Teilen. Schon er allein bekundet, daß man hier einem echten Schriftstellertalent gegenübersteht.

»Und hat das Buch eine Tendenz?« Wie man's nehmen will. Eine religiöse oder politische oder soziale Tendenz hat es nicht, hingegen hat es eine Idee, die vermöge ihrer Wahrheit bestehen wird, wenn alle die jetzt so eifrig verfolgten Tendenzen längst anderen Platz gemacht haben werden. Sie ist die tiefste Seele des Werkes, der Lebensodem, der es durchweht. Ein edler, zu früh dahingeschiedener Dichter hat die Idee mit den Worten ausgesprochen: »Unüberwindlich ist allein der Gute!«

Mit Dank und Freude möge die gebildete Lesewelt diese wertvolle literarische Erscheinung willkommen heißen.

\section{Neue Erzählungen von Marie v. Ebner-Eschenbach}

Ein Schriftsteller, der bereits Treffliches geliefert hat, darf mit vollem Recht erwarten, daß die Kritik seinen ferneren Werken die gebührende Aufmerksamkeit zuwende. Für das Mittelgut, das in der Kunst mit dem Mittelmäßigen sehr nahe verwandt ist, reicht eine flüchtige Anzeige hin, ja vielleicht ist selbst diese überflüssig. Werke von edlerem Gehalt hingegen verdienen eine eingehende Besprechung, eine deutliche Bestimmung des Ranges, den sie in der Literatur einnehmen. Sie würden zwar ohne irgendwelche Vermittlung schließlich ihren Weg machen, denn für alles wahrhaft Gute kommt der Tag, an dem es freudig erkannt wird. Aber diese Erkenntnis zu beschleunigen, ist eine Ehrenpflicht, deren sich die Kritik nicht begeben darf. Marie v. Ebner-Eschenbachs vor kurzem erschienene neue 
Erzählungen sind es, die mich dies lebhaft empfinden lassen. Der Name der Verfasserin mag dem großen Publikum minder geläufig sein, als der so manchen Lohnschreibers; um so besseren Klang hat er bei den gebildeten Lesern, denen er künstlerische Genüsse reinster Art ins Gedächtnis zurückruft.

Der stattliche, ja sogar zu stattliche Band - denn sein Umfang schadet seiner Handlichkeit - enthält vier Erzählungen, unter denen drei von vorzüglichem Werte sind und nur eine nicht auf gleicher Höhe mit den übrigen steht. Ich meine die "Ein kleiner Roman« betitelte, deren Schwäche darin liegt, daß die höchst originell erfundenen und meisterhaft ausgeführten Nebenfiguren dem Leser ein weit lebhafteres Interesse einflößen, als die Hauptpersonen, die nicht mit derselben Schärfe individualisiert sind - ein bei Marie v. Ebner-Eschenbach sehr selten vorkommender Fehler, denn ein wesentlicher Vorzug dieser Schriftstellerin liegt gerade darin, daß sie ihre Gestalten mit einem scharf markierten charakteristischen Gepräge auszustatten weiß. Der Inhalt der Erzählung ist in kurzem folgender: Ein schönes, junges Mädchen tritt in einem vornehmen Hause eine Stelle als Erzieherin des einzigen Töchterchens an. Mit großer Wahrheit ist die Isoliertheit einer solchen Stellung geschildert. In den höheren Ständen sind zwischen der Erzieherin und den Eltern ihrer Zöglinge unsichtbare Schranken gezogen, die nichts zu durchbrechen vermag. An Bildung ihnen wenigstens ebenbürtig, steht sie doch in keinem Verkehr mit ihnen. Man fordert von ihr nur gewisse Kenntnisse und Geschicklichkeiten und den landläufigen Anstand des Benehmens; ihren Charakter kennen zu lernen, hält man für überflüssig; in menschliche Beziehungen $\mathrm{zu}$ ihr zu treten, würde geradezu für unpassend gelten. Von jedem belebenden, anregenden Verkehr abgeschnitten, nie von dem warmen Hauch freundlicher Teilnahme berührt, muß ihr Geist verdumpfen, ihr Herz verknöchern, wenn nicht eine glückliche Fügung sie beizeiten aus dieser trostlosen Thebaide entführt und dem Leben wieder gibt. - In der gräflichen Familie, in der Fräulein Helene fungiert, denkt man am 93 wenigsten daran, dem alten Brauch und Herkommen untreu zu werden. Der Graf selbst, obgleich sonst nicht mit hervorragenden Geistesgaben ausgestattet, ist zwar nicht töricht genug, um zu glauben, er sei aus einem anderen Stoffe geformt, als die gewöhnlichen Menschenkinder; guten, warmen Herzens findet er bei seinen flüchtigen Begegnungen mit Helene manch freundliches Wort für sie. Anders steht es mit seiner Frau, in der das Bewußtsein der Ausnahmsstellung, die Rang und blendende Schönheit 
ihr anweisen, den Hochmut bis zu einem solchen Grade entwickelt hat, $\mathrm{da}$ jeder aus einer anderen Sphäre zu ihr dringender Hauch ihr eine Verunreinigung scheint. Wie eine Olympierin blickt sie auf die sich im Staube Mühenden herab; welche Teilnahme könnten die Leiden und Freuden so untergeordneter Geschöpfe ihr einflößen? Ebenso trefflich ist das Charakterbild von Fräulein Helenens Zögling, Anka, einem überaus seltsam veranlagten Kind, dessen absonderliches Gemütsleben mit solcher Glaubwürdigkeit dargestellt ist, daß man darin ein frappant gelungenes Porträt zu erblicken versucht ist. Gemütsleben sagte ich? Ach nein! Das kleine Ding hat keinen Funken von Gemüt; seelenlos und an fremder Unlust seine Lust findend, erinnert Anka vielfach an die boshaft neckenden Elementargeister der alten Sagen. Sie liebt auf der Welt nichts als ihren Vater und auch diesen nur auf ihre Weise, nämlich als ihr zugehörig. Ihre Mutter ist ihr gleichgiltig und für ihre Erzieherin hegt sie aufrichtigen Haß. Daß Helene zu einem Zögling solchen Schlages kein Herz fassen kann, ist sehr natürlich. Diese gegenseitige, unüberwindliche Abneigung bildet den Angelpunkt der Geschichte, denn als nach dem Tode der Gräfin ihr Witwer, allmählich Helenens Wert erkennend, erst ein lebhaftes Interesse, dann eine tiefe Zuneigung für sie faßt und sich endlich entschließt, um ihre Hand zu werben, tritt dies dämonische oder vielmehr diabolische Kind zwischen Beide. Der Graf täuscht sich über seine Tochter, wie er sich über seine Frau getäuscht hat; er glaubte sich von ihr geliebt, während ihr Herz einem anderen gehörte. Ebenso ergeht es ihm mit Anka, dem bösartigen Kobold, in dem er einen Ausbund von Herzensgüte erblickt. Helene hält sich nicht für berechtigt, ihm den schönen Wahn zu rauben, daß sein Kind der Liebe würdig sei, mit der er es überhäuft. Er könnte diese Liebe doch nun und nimmermehr aus seinem Herzen reißen und innere Kämpfe der bittersten Art wären sein Teil. Und was sollte aus Anka werden, wenn sich zwischen sie und den einzigen Menschen, für den sie Neigung empfindet, eine verhaßte Dritte stellte?

Helene liebt den Grafen, aber diese Erwägungen bestimmen sie, seine Werbung abzuweisen und sein Haus zu verlassen. Sie handelt gewiß vernünftig, nur mag man bezweifeln, daß ein von einer starken, tiefen Neigung erfülltes Gemüt solche Vernunftschlüsse ziehen und sich ihnen unterwerfen dürfte. Warum kommt Helenen nicht der sehr naheliegende Gedanke: »Der Mann, den ich liebe, ist leicht zu täuschen. Um so mehr tut es not, daß ein klarer blickendes, ihm treu ergebenes Wesen ihm zur Seite stehe und ihn vor seiner eigenen Leichtgläubigkeit schütze. Und 
sollte auch alles, woran er sich jetzt klammert, unter seinen Händen zerbröckeln, ich bleibe ihm. « Meines Erachtens wäre diese Auffassung natürlicher und eben deshalb sympathischer. Die schwächste Figur in der Erzählung ist der Graf, der, wie mit einer Binde vor den Augen durchs Leben, nicht nur nichts sieht, sondern auch nichts sehen will. Wenn die Erzählerin ausruft: »Die Welt verlacht die Betrogenen, ich liege vor ihnen auf den Knien, " so scheint mir dies ein nicht zu billigender Kultus der Verblendung. Der Mangel an Urteilskraft, die Scheu, der Wahrheit ins Gesicht zu blicken, können doch unmöglich für verehrenswürdige Eigenschaften gelten. Vielleicht würde man die gerügten Schwächen weniger empfinden, wenn nicht die Nebenfiguren, vor allem die egoistische und frivole Schwiegermutter des Grafen, mit solcher Lebenswahrheit, mit solcher Feinheit der Beobachtung dargestellt wären, daß die eigentlichen Träger der Handlung daneben verblassen. Zählt diese Arbeit auch nicht zu den vorzüglichsten der reichbegabten Verfasserin, so enthält sie doch Charakterbilder von solcher Treue und Präzision und so viele reizende 96 Details, daß, wenn sie auch als Ganzes hinter den übrigen zurückbleibt, es dennoch wohl getan war, sie in diese neue Sammlung aufzunehmen.

Unbedingte Anerkennung gebührt der folgenden Erzählung: »Die Freiherren v. Gemperlein. « Man kann sich keine liebenswürdigere Humoreske denken. Zwei Brüder, Ludwig und Friedrich v. Gemperlein, die Letzten ihres Stammes, führen auf dem alten Familiengut Wlastowiz ein Junggesellenleben. Die innigste Bruderliebe fesselt sie unauflöslich aneinander, verhindert aber dennoch nicht, daß des Zanks und Haders zwischen ihnen kein Ende ist. Die Gemperlein waren von jeher ein streitbares Geschlecht; in seinen letzten Ausläufern tritt diese Stammeseigenheit noch gesteigert hervor. Keiner könnte den anderen entbehren, doch ebensowenig können sie sich friedlich vertragen, ja vielleicht würde ihr Verkehr einen Teil des Reizes, den er für sie hat einbüßen, wenn sie durch irgendein Wunder plötzlich Eines Sinnes würden. An Schrullen und Phantastereien stehen sie sich vollkommen gleich, nur verfolgen diese ganz entgegengesetzte Richtungen. Friedrich ist streng konservativ und von aristokratischen Anschauungen erfüllt, während Ludwig zur Fahne des Radikalismus geschworen hat und zwischen den Menschen keinen anderen Unterschied gelten lassen will, als den ihres persönlichen Wertes. Bei vielen sehr sinnreich herbeigeführten Anlässen prallen diese entgegengesetzten An97 sichten mit aller Heftigkeit und höchst ergötzlich aneinander. Ludwig beschließt, seine Grundsätze praktisch durchzuführen; er will die Tochter 
eines Kaufmannes im benachbarten Städtchen heiraten. Er kennt sie zwar nur ganz flüchtig, aber seine immer rege Phantasie spiegelt ihm vor, daß sie wie er in dieser Ehe ihr Glück finden.

Man kann sich Friedrichs Entrüstung vorstellen, als er von diesem Projekt erfährt. Er schwört hoch und teuer, daß seine künftige Gemahlin nie die Schwelle der geborenen Äpelblüh betreten werde und zwischen seinen $\mathrm{zu}$ erhoffenden Kindern und denen seines Bruders absolut kein Verkehr stattfinden dürfe. Ludwig trägt sich nämlich gleichfalls mit Heiratsgedanken und späht in dem genealogischen Taschenbuch der gräflichen Häuser nach einer ebenbürtigen Gemahlin aus. Besagtes Taschenbuch spielt ihm jedoch in aller Unschuld einen schmählichen Streich. Als er eben im Begriffe ist, nach Schlesien, der Heimat der Auserkorenen, zu reisen, erfährt er, daß sie gar nicht existiert und daß er jahrelang für einen Druckfehler geschwärmt hat. Auch Ludwigs Bewerbung ist verunglückt, bevor sie vorgebracht wurde. Die Brüder trösten sich über ihr Mißgeschick, indem sie einander gegenseitig verspotten. Nach Jahren ferneren Zusammenlebens droht es zu einer wirklichen Entzweiung zwischen ihnen zu kommen. Beide fassen eine Neigung zu der auf Besuch hier verweilenden Nichte einer Gutsnachbarin. Anfangs will keiner dem anderen weichen, als es aber, wie sie meinen, zur Entscheidung kommen soll, will keiner auf Kosten des anderen glücklich werden. Jeder wirbt hinter dem Rücken des Bruders für denselben um die Hand jener reizenden Nichte, die nun, in die Enge getrieben, gesteht, bereits seit Jahren verheiratet zu sein. Ihre nur auf den eigenen Spaß bedachte Tante hat sich ihren Nachbarn gegenüber eine kleine Mystifikation erlaubt. In so energischen Naturen läßt jedoch keine Enttäuschung eine dauernde Spur zurück und neue Hoffnungen treten an die Stelle der zerstörten. So auch hier. Die Freiherren beharren in der Zuversicht, endlich doch die Rechte zu finden, bis sie von hinnen scheiden und mit ihnen der Name Gemperlein ausstirbt.

Dies der Stoff der Erzählung. Man muß sie selbst lesen, um sich zu überzeugen, welchen Reiz ihm die geist- und humorvolle Behandlung verleiht. Die beiden Hauptcharaktere sind bei aller ihrer Absonderlichkeit so lebenswahr, ihre Schrullenhaftigkeit kann den Adel ihrer Gesinnung, ihre reine Herzensgüte so wenig beeinträchtigen, daß man, wenn man sie auch häufig belächelt, sie nichtsdestoweniger lieben und verehren muß. Nur eine sehr geschickte Hand konnte die in ihrem Wesen liegenden Widersprüche mit solcher überzeugender Kraft harmonisch auflösen, und eines überaus richtigen Geschmacks bedurfte es, um diese Physiognomien 
99 weder abzuschwächen, noch in Übertreibungen zu verfallen. Derselbe feine Takt bewährt sich in Nebenfiguren; sie, besonders die würdige Frau Kurzmichel, wirken komisch, nicht possenhaft, weil sie eben in keinem Moment aufhören, mögliche Menschen zu sein. Und wie meisterlich erzählt ist das Ganze, wie natürlich, wie anmutig, mit wie heiterem Witz! Um dergleichen zustande zu bringen, muß man nebst einem großen Takt auch noch ein tiefes Verständnis des Besten im menschlichen Gemüt und eine liebevolle Nachsicht für menschliche Verkehrtheiten besitzen.

In »Lotti, die Uhrmacherin", werden ernstere Saiten angeklungen. Diese Erzählung, die vor ein paar Jahren in Rodenbergs »Deutscher Rundschau « zuerst erschien, fand schon damals die Anerkennung, die sie vermöge ihres geistigen Gehalts und ihrer edlen Form in vollstem Maße verdient. Der Gedanke, der ihr zugrunde liegt, ist, daß durch Fleiß und unbedingte Hingebung das Handwerk fast zur Kunst geadelt werden kann, und die Kunst hinwieder zum Handwerk herabsinkt, wenn sie mit unlauterem Sinne geübt wird. Jenes Aufwärtsstreben zeigt sich uns in Lotti, die das Gewerbe, das sie von ihrem Vater, einem ausgezeichneten Uhrmacher, erlernt hat, mit solcher Liebe, ich möchte sagen mit solcher Begeisterung betreibt, daß ihr schlichtes, in Arbeit verbrachtes Leben dadurch Reiz und Bedeutung gewinnt. Den Gegensatz zu ihr bildet Hermann Halwig, ein junger Poet von ungewöhnlichem Talent. Als Lotti ihn kennen lernt, weiß noch niemand von ihm, aber bald soll die Sonne des Ruhmes für ihn aufgehen. Sein erster literarischer Versuch dringt siegreich durch, die zweite Dichtung, die er veröffentlicht, macht ebenso großes Glück - nun zögert er nicht länger, dem Staatsdienst Valet zu sagen und sich ausschließlich der Kunst zu widmen. Lotti, um die er im Jubel seines ersten Triumphes geworben, liebt ihn von ganzer Seele, und er? Nun er glaubt, sie zu lieben, bis teils sein weltlicher Sinn, teils seine gekränkte Eitelkeit den schwachen Funken erlöschen machen. Sobald Lotti des inne geworden, tritt sie entschlossen zurück und gibt ihm seine Freiheit wieder, - nicht ohne schwere innere Kämpfe, aber von dem Bewußtsein gestärkt, das einzig Richtige erwählt zu haben. Jahre vergehen, bis der Friede in Lottis Herz zurückkehrt und die ihr angeborene heitere Ruhe wieder aus ihren Zügen lächelt. Halwig ist inzwischen ein berühmter Schriftsteller geworden, den die Verleger bestürmen, ihnen seine Werke zu überlassen. Er geht auf die glänzenden Anerbietungen, die ihm von allen Seiten gemacht werden, um so bereitwilliger ein, als er sich vor einiger Zeit mit einem an Eleganz und Luxus gewöhnten jungen Mädchen vornehmen Standes 
vermählt hat, einem jener kindischen, gedankenlosen Geschöpfe, denen das Überflüssigste für ganz unentbehrlich gilt und die, ohne Böses zu wollen, vampyrgleich Blut und Mark des Mannes aussaugen, dessen Schwäche sie gewähren läßt. Jetzt heißt es Geld, möglichst viel Geld verdienen; Erwerb ist fortan das einzige Ziel, das Halwig vor Augen schwebt. Er traut seinem Talent unerschöpfliche Ergiebigkeit zu; der Gedanke, daß es ihm je den Dienst versagen könne, kommt ihm nicht in den Sinn. Unablässig schreibt und schreibt er, ohne Schaffensdrang, nur dem Gebot einer äußeren Notwendigkeit gehorchend. Dank den Wundern, die der Pinsel Mings' bewirkt, finden seine Arbeiten trotz ihrer zunehmenden Flüchtigkeit und Verschlechterung noch immer reißenden Absatz. Aber um welchen Preis? Ihm selber wird klar, daß ihm auf dieser Hetzjagd nach Geld und Gut das Gefühl für das Schöne verloren ging; wie sollte er da noch Schönes schaffen können? Wohlan! wenn er nicht mehr fähig ist, ein edles Kunstwerk hervorzubringen, so sei es denn mit dem Sensations- und Skandalroman versucht - diese Ware findet ja unter allen Umständen Liebhaber ohne Zahl. - Lotti, mit der er durch einen Zufall wieder in Verbindung getreten ist, sieht ihn mit tiefem Seelenschmerz dem gänzlichen Ruin entgegeneilen. Sie liebt ihn längst nicht mehr, aber die Erinnerung an eine ferne, schöne Zeit ist ihr wert und teuer geblieben. Großherzig bringt sie ein schweres, schweres Opfer, um ihn von schmachvollen Verpflichtungen zu befreien, die er eingegangen ist. Umsonst! Es duldet Halwig nicht lange in dem Asyl, das seine edle Freundin ihm bereitet hat. Die Aufregungen der Literaten-Existenz sind ihm zum Bedürfnis geworden; er dürstet nach ihren Bitternissen und stürzt sich neuerdings in den Strudel, der ihn in die Tiefe hinabreißen muß.

Das passendste Motto für diese Erzählung wäre ein Ausspruch, der sich in den früher erschienenen "Aphorismen « derselben Verfasserin befindet. Er lautet: »Der Charakter des Künstlers ernährt oder verzehrt sein Talent.« So ist es. Die glänzendsten Gaben bleiben fruchtlos, wenn ihnen nicht die sittliche Kraft beigesellt ist, die bei der Produktion lieber auf den Beifall der ganzen Welt, als auf die eigene Zustimmung verzichten würde. Von der Natur vor Tausenden erkoren, geht der Poet dieser Gnadenwahl verlustig, sobald er sich in den Dienst der gemeinen Mächte des Lebens begibt. Der Mahn- und Warnungsruf, der aus dieser Erzählung tönt, kommt wahrlich zur rechten Zeit. Sehen wir nicht jetzt so manche, die zu Höherem berufen waren, frevelhaften Mißbrauch mit ihrem Talent treiben und im gierigen Hasten nach Gewinn dem geistigen und moralischen Bankerott 
zusteuern? Halwigs Gestalt ist ein Typus, der ganz und gar der Gegenwart angehört und eine ihrer traurigsten Seiten repräsentiert: Der Poet, in dem der Glaube an seine Mission erloschen ist, der, statt allem Volk voranzu103 schreiten, es vorzieht, sich in den gemeinen Haufen $\mathrm{zu}$ mischen und dessen wüste Leidenschaften noch anzufachen. Im wohltuenden Gegensatz $\mathrm{zu}$ dem, allem Idealen entfremdeten Halwig, sind Lotti und Gottfried wahre und wirkliche Idealisten. Allerdings ist ihre Sphäre eine bescheidene, aber es handelt sich nicht darum, was der Mensch betreibt, sondern in welchem Sinne, mit welchem Grad von Hingebung an sein Werk es geschieht. Treues Bemühen, strenge Gewissenhaftigkeit adeln jede Beschäftigung. Das wichtige ist, daß der Mensch auf alles, was er schafft, die Sorgfalt wende, die nicht ruht noch rastet, bis auch der kleinste, keinem anderen Auge sichtbare Makel beseitigt ist.

Die Verfasserin hat es verstanden, uns bis ins innerste Herz dieser einfachen und zugleich großsinnigen Menschen blicken zu lassen. Auch die übrigen Figuren sind von überzeugender Lebenswahrheit erfüllt, Halwig selbst, seine trotz aller inneren Leerheit verführerische Frau, der kluge und wackere Advokat Schweizer, ja selbst die Gestalten, die nur ganz episodisch auftauchen, ohne weiter in die Handlung einzugreifen, sind oft nur mit ein paar Strichen scharf charakterisiert. Dabei ist der Ton der Erzählung so überaus anmutig, sie enthält so viele reizende Einzelheiten, daß der tiefe Ernst des Grundgedankens dadurch ein entsprechendes Gegengewicht erhält.

In »Nach dem Tode« sehen wir einen eigentümlichen psychologischen

104 Prozeß sich vollziehen. Natur und Schicksal haben sich verbunden, um den jungen Grafen Paul Sonnberg mit ihren besten Gaben zu überhäufen. Den Menschen jedoch, zumal wenn er von Haus aus tüchtig ist, kann ein Glück nicht befriedigen, das er nicht durch eigene Anstrengung errungen hat. Noch mehr: das ewige Gesetz, daß uns Edles und Köstliches nur um den Preis fortgesetzter Bemühungen genießen läßt, ist so tief in unser Herz gegraben, daß auch nur die Liebe, um die wir erst werben, deren wir uns erst würdig zeigen müssen, uns wahrhaft beglücken kann. An Paul bewahrheitet sich diese Erfahrung. Von seinen Eltern und seiner Frau abgöttisch geliebt, ohne daß er je das Geringste getan hätte, um solche Zärtlichkeit zu verdienen, fühlt er sich von derselben erdrückt und vergilt sie mit rauher Gleichgiltigkeit. Er ergreift die erste Gelegenheit, die sich ihm bietet, sich von den Seinen loszureißen und eine bewegtere Existenz aufzusuchen. Kurz nach seinem Scheiden stirbt seine junge Frau, 
nachdem sie einem Töchterchen das Leben geschenkt hat. Nach Beendigung des Feldzuges, den Paul als Freiwilliger mitgemacht hat, widmet er sich der parlamentarischen Laufbahn und erringt auf derselben glänzende Erfolge, die ihn zu der Hoffnung auf eine große Zukunft berechtigen. Keine Sehnsucht nach seinen bejahrten Eltern, nach dem Anblick seines Kindes regt sich in seinem Gemüt. Da überkommt ihn plötzlich eine tiefe Leidenschaft für die schöne Gräfin Thekla Neumark und mit dieser Leidenschaft erschließt sich ihm eine Welt von Gefühlen, von denen er bis dahin nichts ahnte. Thekla ist eine jener kühlen Frauennaturen, die sich gewiß nie eines Fehltrittes schuldig machen werden, aber auch unfähig sind, jemals eine jener begeisterten Regungen $\mathrm{zu}$ empfinden, die das Göttliche im Menschen bekunden. Sie liebt Paul nach ihrer Weise, d.h. sie weiß seine persönlichen Vorzüge zu würdigen, wenn sie ihn auch etwas zu überspannt, zu exaltiert findet. Nebenbei schmeichelt es ihrer Eitelkeit, die brillanteste Partie im Lande zu machen. Eine Weile hindurch trachtet Paul, sich über ihr eigentliches Wesen zu täuschen; als ihm dies nicht mehr gelingen will, sucht er Entschuldigungen dafür, und wann wäre die Leidenschaft verlegen, deren $\mathrm{zu}$ finden? Eines aber tritt ihm doch klar und unwiderleglich entgegen: daß er, zum erstenmal in seinem Leben, inniger liebt, als er geliebt wird und unendlich mehr gibt, als er empfängt. Wenn diese Erkenntnis auch seiner Leidenschaft für Thekla nichts anhaben kann, so ruft sie doch das Bild vergangener Tage in ihm zurück. Erst nur flüchtig und traumhaft zieht die Gestalt der längst im Grabe schlummernden Marie an ihm vorüber und Reue beschleicht ihn bei dem Gedanken, wie oft er dieses treue, ihm ganz ergebene Herz durch Kälte und Mißachtung gekränkt hat. Die Liebe zu einem Einzelwesen, die bei gewöhnlichen Menschen den Egoismus noch steigert, bringt bei Paul, wie bei allen edlen Naturen die entgegengesetzte Wirkung hervor: sie befreit ihn von den Fesseln der Selbstsucht und ruft heiliges Mitleid mit aller Kreatur in ihm wach. Die Wandlung ist bereits zur Hälfte vollzogen, als Paul sich zu kurzem Bezug, wie er meint, nach Schloß Sonnberg begibt; dort gelangt sie zu ihrem Abschluß. Die Spuren von Mariens Erdenwallen sind es, die seine künftige Bahn bestimmen. Leidenschaft und Ehrgeiz verstummen vor der Stimme, die aus dem Jenseits zu ihm spricht. Auf seine bisherigen Lebensziele verzichtend, sucht Paul den einzig möglichen Ersatz für das von ihm verscherzte Glück in der Hingebung an die Seinen und in treuer Pflichterfüllung. 
Mit großer Feinheit und Umsicht hat die Verfasserin das Problem einer solchen inneren Umgestaltung gelöst. Paul wird nicht etwa unversehens ein anderer Mensch, als er bisher gewesen ist; es entwickeln sich in ihm nur die edlen Keime, die von jeher in ihm lagen und die sich ohne die Verwöhnung, deren Gegenstand er war, schon früher entfaltet hätten. Kaum wird die Kraft der Liebe in ihm geweckt, so treiben sie volle, reiche Blüten. - Die erste Hälfte der Erzählung spielt in den Kreisen der vornehmen Gesellschaft, die zweite auf dem Lande. Bei diesem Wechsel des Schauplatzes ist dem Leser zu Mute, als würde er aus einer von Schemen 107 bevölkerten Welt in die wahre wirkliche versetzt, in der die Natur ihr Recht behauptet und der Mensch nach eigenen Impulsen handelt, während in jenen Kreisen Scheinwesen und Konvenienz keine Ursprünglichkeit aufkommen lassen. Thekla vor allem kann als ein mustergiltiges Produkt jener Drillung gelten, deren höchstes Ziel tadellose Korrektheit ist. So betrachtet auch ihre Mutter, obgleich eine weichere, edlere Natur, die Schwärmerei - und wie dehnbar ist dieses Wort! - als die Wurzel alles Übels. Kein ernstes Wort findet in dieser exklusiven Gesellschaft den leisesten Anklang, die Interessen lassen sie gleichgiltig und dennoch erscheint sie in dieser Darstellung von dem bestrickenden Zauber jener äußeren Liebenswürdigkeit umgeben, den die vollendete Anmut der Umgangsformen verleiht. Nur ein an Welterfahrung reicher Geist konnte dieses Lebensbild entwerfen, nur eine Künstlerhand Licht und Schatten so richtig verteilen und bei solcher Fülle von wechselnden Szenen das Einheitliche der Konzeption so unbeirrbar wahren.

Marie v. Ebner ist mehr als eine talentvolle Schriftstellerin, sie ist durch und durch eine echte Künstlerin, die nicht mit der Hoffnung auf zufälliges Gelingen, sondern mit zielbewußtem Wollen an die Arbeit geht. Wohl wissend, daß nur mittels der Form das Schöne uns bewußt werden kann, pflegt sie dieselbe mit einer bis ins Kleinste gehenden, sich aber nie ins 108 Kleinliche verlierenden Sorgfalt. Ihr Stil ist von seltener Reinheit, Frische und Natürlichkeit, die Führung des Dialogs so lebendig, daß sich in kurzen, abgerissenen Sätzen oft ein ganzer Charakter ausspricht. Hier hat sich einmal ein großes Talent mit einem seiner würdigen Gemüt zusammengefunden. Nicht dem Talent allein, sondern auch dem sich nie verleugnenden Adel der Gesinnung, der warmen Menschenliebe, deren wohltuenden Hauch man in jedem Worte spürt, verdanken Marie v. Ebners Schriften den Zauber, den sie auf den Leser ausüben. 
Vielleicht ist der Umstand, daß die Verfasserin den Schauplatz ihrer Erzählungen ausnahmslos nach Österreich, ihrer Heimat, verlegt, als eine Mitursache des Reizes derselben zu betrachten. Die genaue Kenntnis, die sie von Land und Leuten besitzt, ihre Vertrautheit mit den Verhältnissen, wie mit der Sinnes- und Gemütsart der Menschen, in deren Mitte sie aufwuchs und sich entwickelte, verleihen ihren Darstellungen eine Treue und eine Lebensfülle, die aus der Phantasie allein nicht geschöpft werden können. Man mag wohl auch fremde Länder durch Studium und Beobachtung kennen lernen, ganz und voll versteht man aber doch nur das Heimatliche. Aus Marie v. Ebners Büchern quillt es dem Leser wie frischer Erdgeruch entgegen - es ist der Duft der heimatlichen Scholle. Die Gestalten, die sie uns vorführt, fußen auf einem realen, mit ihrem ganzen Wesen übereinstimmenden Boden und tragen bei der schärferen Individualisierung einen unverkennbaren Zug von Stammverwandtschaft im Antlitz. Auf die Ausprägung dieser nationalen Eigenheiten Gewicht zu legen, ist ein Verdienst der neueren Novellistik. Wie wenig wurden früher in der Kunst die sozialen, klimatischen und genetischen Einflüsse in Anschlag gebracht! Spielte die Handlung in Deutschland, so begnügte man sich, als Ort derselben »eine deutsche Stadt« anzugeben. Als wenn die deutschen Städte sich untereinander glichen wie Biberansiedlungen. Als wenn es gleichgiltig wäre, ob München oder Königsberg der Schauplatz der Begebenheiten. Daß man den Zusammenhang der Menschen mit der Natur, die sie umgibt, ihre Abhängigkeit von der geistigen Atmosphäre, in der sie leben, jetzt um so viel mehr beachtet, ist ein tröstliches Zeichen zunehmenden Lebens- und Wahrheitsgefühls.

Zum Schlusse kann ich mirs nicht versagen, die Leser dieses Aufsatzes wiederholt auf Marie v. Ebners »Aphorismen« (Berlin, Fr. Ebhardt, 1880) hinzuweisen. Das Büchlein enthält einen wahren Schatz von tiefen, edlen und originellen Gedanken und feinen Wahrnehmungen, die durch die knappe, präzise, fast epigrammatische Form noch den Reiz des Pikanten erhalten. Zum Beweise dessen erlaube ich mir, hier einige Stichproben zu bringen: "Sei Deines Willens Herr und Deines Gewissens Knecht. - »An das Gute glauben nur die Wenigen, die es üben." - »Wer an die Freiheit des menschlichen Willens glaubt, hat nie geliebt und nie gehaßt.« - »Der Maßstab, den wir an die Dinge legen, ist das Maß unseres eigenen Geistes.« - »Dem großen Publikum ist ein Buch nicht leicht zu schlecht, sehr leicht zu gut.« - »Wo wäre die Macht der Frauen, wenn die Eitelkeit der Männer nicht wäre!« - »Schwächliche Grämlichkeit, die alle fünf gerade 
sein läßt, ist die Karrikatur der Resignation.« - »Die größte Nachsicht mit einem Menschen entspringt aus der Verzweiflung an ihm."

Ich hoffe, durch die angeführten Aussprüche in meinen Lesern wenigstens annähernd die Vorstellung erweckt zu haben, wie vielfältige Anregungen dies merkwürdige Büchlein gibt. Wer sich an Marie v. Ebners Erzählungen erfreut, der zögere nicht, ihre »Aphorismen « kennen zu lernen; sie werden ihn einen Blick in ihr eigentlichstes Wesen tun lassen. 